\title{
mRNA Expression of the ATP-Binding Cassette Transporter Subfamily A (ABCA) in Rat and Human Brain Capillary Endothelial Cells
}

\author{
Sumio Ohtsuki,${ }^{a, b, c}$ Yuki Watanabe, ${ }^{a}$ Satoko Hori, ${ }^{a, b, c}$ Hiroya Suzuki,${ }^{a}$ Jiraganya Bhongsatiern, ${ }^{a}$ \\ Masachika FuJIYoshi, ${ }^{a}$ Mayu KamoI, ${ }^{a}$ Naoko KamiYA,${ }^{a, b, c}$ Hitomi TAKANAGA, ${ }^{a, b, c}$ and \\ Tetsuya TERASAKI ${ }^{*, a, b, c}$ \\ ${ }^{a}$ Department of Molecular Biopharmacy and Genetics, Graduate School of Pharmaceutical Sciences, Tohoku University; \\ ${ }^{b}$ New Industry Creation Hatchery Center, Tohoku University; Aoba, Aramaki, Aoba-ku, Sendai 980-8578, Japan: and \\ ${ }^{c}$ CREST and SORST of the Japan Science and Technology Agency (JST); Japan. \\ Received April 13, 2004; accepted July 6, 2004; published online July 8, 2004
}

The ATP-binding cassette transporter subfamily A (ABCA) consists of the transporters mediating cholesterol release and regulated by cholesterol. As about $25 \%$ of total body cholesterol exists in the brain, sterol homeostasis is an important issue as far as central nervous system function is concerned. The purpose of this study was to clarify the mRNA expression of ABCA subtypes at the blood-brain barrier (BBB) using cultured rat and human brain capillary endothelial cells, TR-BBB and hBME cells, respectively. mRNA expression of ABCA1, 2, $3,4,5,6,7$ and 8/9 was detected in TR-BBB cells. In the brain capillary-rich fraction, mRNA expression of ABCA1, 2, 3, 4, 5, 7 and 8/9 was detected. ABCA2 and 5 mRNA were also detected in hBME cells. These results demonstrate, for the first time, that $\mathrm{ABCA}$ subtypes are expressed at the rat and/or human $\mathrm{BBB}$. The expression of ABCA subtypes at the BBB is likely to contribute to sterol homeostasis in the central nervous system.

Key words ATP-binding cassette transporter subfamily A (ABCA); blood-brain barrier (BBB); mRNA expression; brain capillary endothelial cells; TR-BBB; hBME

The ATP-binding cassette $(\mathrm{ABC})$ transporter subfamily A (ABCA) belongs to the ABC transporter superfamily, which also includes multidrug resistance protein 1 (MDR1/AB$\mathrm{CB} 1)$, multidrug resistance associated proteins (MRP/ABCC) and breast cancer resistance protein (BCRP/ABCG2). One of the unique characteristics of the ABCA transporters is their involvement in sterol transport. ABCA1 and 7 mediate Apo-AI-dependent cholesterol release from cells, ${ }^{1,2)}$ and the ABCA1 mutation is linked to genetic diseases, such as Tangier disease, associated with a high density lipoprotein deficiency. ${ }^{3)}$ The mRNA levels of ABCA2, 3 and 7 have been reported to be up-regulated by cholesterol, ${ }^{4-6)}$ also suggesting involvement of ABCA transporters in sterol transport processes.

Brain capillary endothelial cells (BCECs) form the blood-brain barrier (BBB) with tight junctions. BCECs regulate exchange between blood and brain by expressing various transporters, including MDR1/ABCB1, MRP/ABCC and $\mathrm{BCRP} / \mathrm{ABCG} 2$. $^{7)}$ Sterols, especially cholesterol, are important components of the central nervous system (CNS). Indeed, about $25 \%$ of total body cholesterol is in the brain. ${ }^{8)}$ It has been reported that primary cultured porcine BCECs express $\mathrm{ABCA} 1$, and are involved in the release of cholesterol from cells.9) This report proposes the hypothesis that the BBB plays an important role in sterol homeostasis in the brain. Abnormalities in sterol homeostasis have been reported to be associated with a number of neurodegenerative diseases, including Alzheimer's disease. ${ }^{8}$ Therefore, clarifying the expression of ABCA subtypes in BCECs could be an important contribution to our understanding of the function of the BBB and sterol homeostasis in the CNS.

Cultured BCECs are a useful tool for examining the expression and regulation of transporters at the BBB. We have established several lines of conditionally immortalized BCECs (TR-BBB) from a transgenic rat harboring tempera- ture-sensitive SV40 large T-antigen gene. ${ }^{10,11)}$ TR-BBB cells express transporters including mdrla/ABCB1, mrp1/ABCC1 and $\mathrm{BCRP} / \mathrm{ABCG} 2$, and also retain the functions of the in vivo $\mathrm{BBB} .{ }^{12,13)} \mathrm{hBME}$ cells are cultured human brain microvascular endothelial cells, which also express BBB transporters, including MRP1, and retain amino acid transport activity. $^{14)}$

The purpose of this study was, therefore, to investigate the expression of ABCA subtypes in rat and human BCECs by using TR-BBB and hBME cells.

\section{MATERIALS AND METHODS}

Animals Adult male Wistar rats, weighing 230 to $280 \mathrm{~g}$, were purchased from Charles River Laboratories (Yokohama, Japan). All experiments were approved by the Animal Care Committee, Graduate School of Pharmaceutical Sciences, Tohoku University.

Cell Culture TR-BBB cells and hBME cells were cultured as described previously. ${ }^{10,14)}$ Briefly, TR-BBB11 and 13 cells were grown in Dulbecco's modified Eagle's medium (DMEM, Nissui Pharmaceutical, Tokyo, Japan) supplemented with $20 \mathrm{~mm}$ sodium bicarbonate, $15 \mu \mathrm{g} / \mathrm{ml}$ endothelial cell growth factor, $100 \mathrm{U} / \mathrm{ml}$ benzylpenicillin potassium, $100 \mu \mathrm{g} / \mathrm{ml}$ streptomycin sulfate and $10 \%$ fetal bovine serum (Moregate, Bulimba, Australia) onto collagen type I-coated tissue culture dishes (BD Biosciences, Franklin Lakes, NJ, U.S.A.) at $33{ }^{\circ} \mathrm{C}$ in a humidified atmosphere of $5 \% \mathrm{CO}_{2}$ in air.

hBME cells provided by the Applied Cell Biology Research Institute (Kirkland, WA, U.S.A.) were purchased from Dainippon Pharmaceutical (Osaka, Japan). hBME cells were cultured in CS-C Complete Serum-Free medium kit (Cell Systems Corporation, Kirkland, WA, U.S.A.). hBME cells were grown in collagen type I-coated tissue culture dishes 
Table 1. Primer Sets Used for RT-PCR

\begin{tabular}{llr}
\hline \hline & Sense primer sequence & Annealing \\
& Antisense primer sequence & $\begin{array}{r}\text { temperature } \\
\text { Product size }\end{array}$ \\
& & \\
\hline \multirow{2}{*}{ A1-1 } & TGAATAATATCAATGATATCCTGAAGTCCG & $60^{\circ} \mathrm{C}$ \\
& GGGTTGGACCCTGCTAATCGTACAACT & $1063 \mathrm{bp}$ \\
A1-2 & CGGTTGAAGGAGACCATGCGCATC & $60{ }^{\circ} \mathrm{C}$ \\
& CCCATTGGACCCCGATGCCTTGCT & $424 \mathrm{bp}$ \\
A2 & CCCGGAAGATTGGCCGTATCCTGG & $60^{\circ} \mathrm{C}$ \\
& TTGAAGGACAGCTGGGCCCGC & $1124 \mathrm{bp}$ \\
A3 & GGCTTCCTCTACTTCTTCACCTA & $60{ }^{\circ} \mathrm{C}$ \\
& GGAAGACCACCACCCTCTCCA & $823 \mathrm{bp}$ \\
A4-1 & AGCGCTTCATCATCTTCAGCCA & $55^{\circ} \mathrm{C}$ \\
& TGACTCCAGGCTCTGGATCAATG & $506 \mathrm{bp}$ \\
A4-2 & AGGTCACCCTACAGTGGATAGAAG & $65^{\circ} \mathrm{C}$ \\
& TGTGGAATCAATCCCCAGGAAGGC & $362 \mathrm{bp}$ \\
A5 & GATGATTCACTGAAGTGTATGGGTTA & $60^{\circ} \mathrm{C}$ \\
& ATCTTAACTGCCCAGACACCATGAT & $718 \mathrm{bp}$ \\
A6 & CAGTTCAGTTTTGGGCCACCTGGG & $60{ }^{\circ} \mathrm{C}$ \\
& CTCAAACATAGGGGTGATAGCAAACCT & $1046 \mathrm{bp}$ \\
A7-1 & AGTAGTGGCTCGGCCTCCATCCTG & $55^{\circ} \mathrm{C}$ \\
& AGCTCTGCCTCATCCAGGTGGTG & $428 \mathrm{bp}$ \\
A7-2 & GCCATGACGTGCAAACCAACATG & $55^{\circ} \mathrm{C}$ \\
& AGTGGAGAGGATCAGTGTCCGAC & $380 \mathrm{bp}$ \\
A8/9-1 & CTTCTAGATGAGCCGTCCACTGGG & $55^{\circ} \mathrm{C}$ \\
& ATCAGAGAAGAGTACCGTTCCTGCC & $329 \mathrm{bp}$ \\
& AGGCGATCCGGGCCACTTTTAC & $62{ }^{\circ} \mathrm{C}$ \\
& TTGAGCGACTCCACCAGAGCCG & $214 \mathrm{bp}$ \\
& & \\
& & \\
& &
\end{tabular}

Primer sets A1-1, A4-1, A7-1 and A8/9-1 were used for RT-PCR analysis in TRBBB cells, and primer sets A1-2, A4-2, A7-2 and A8/9-2 were used in rat brain capillary rich fraction.

(BD Biosciences) at $37^{\circ} \mathrm{C}$ in a humidified atmosphere of $5 \%$ $\mathrm{CO}_{2}$ in air.

Brain Capillary-Rich Fraction Isolation of the rat brain capillary-rich fraction was performed as described previously. ${ }^{10)}$ Briefly, cerebrum excised from rats was dissected into pieces, and homogenized in phosphate-buffered saline (PBS). Homogenate was added to the same volume of $32 \%$ dextran solution, and then centrifuged $(4500 \times \boldsymbol{g}, 20 \mathrm{~min}$, $4^{\circ} \mathrm{C}$ ). The resulting pellets were washed in PBS to obtain the enriched capillary fraction. The mRNA level of ABCG2, which is selectively localized at BCECs in rat brain, in the fraction was enriched 34.7-fold compared with that in whole brain. ${ }^{15)}$

RT-PCR Analysis Total RNA was prepared from TRBBB cells, hBME cells and brain capillary-rich fraction using TRIzol reagent (Life Technologies, Grand Island, NY, U.S.A.) according to the manufacturer's protocol. Human brain cDNA was purchased from Clontech (Palo Alto, CA, U.S.A.). Single-stranded cDNA was made from $1 \mu \mathrm{g}$ total RNA by reverse-transcription (ReverTraAce, Toyobo, Osaka, Japan) using oligo dT primer. Primer sets were designed from the regions in which the nucleotide sequence was conserved in humans and mice, since, at the time the RT-PCR analysis was conducted, the nucleotide sequence of the rat ABCA subtypes was not available. PCR was conducted with the specific primer sets (Table 1) through 1 cycle of $94^{\circ} \mathrm{C}$ for $2 \mathrm{~min}$, and 35 cycles of $94^{\circ} \mathrm{C}$ for $30 \mathrm{~s}$, annealing temperature (Table 1) for $1 \mathrm{~min}$, and $72{ }^{\circ} \mathrm{C}$ for $1 \mathrm{~min}$, then $72{ }^{\circ} \mathrm{C}$ for a further $10 \mathrm{~min}$. The RT-PCR products were separated by elec-

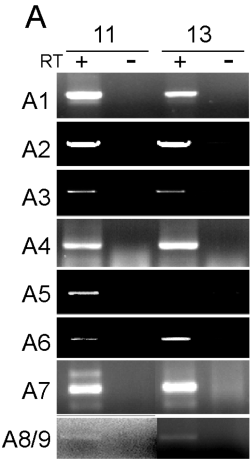

B

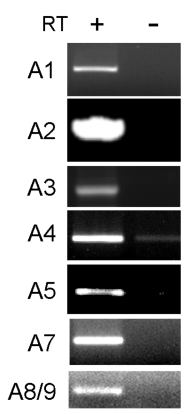

Fig. 1. mRNA Expression of ABCA Subtypes in TR-BBB Cells and Rat Brain Capillary-Rich Fraction

(A) mRNA expression in TR-BBB11 (11) and TR-BBB13 (13) cells. RT-PCR analysis was performed with specific primer sets shown in Table 1. For ABCA1, 4, 7 and 8/9 detection, primer sets A1-1, A4-1, A7-1, A8/9-1 were used, respectively. (B) mRNA expression in rat brain capillary-rich fraction. For ABCA1, 4, 7 and $8 / 9$ detection, primer sets A1-2, A4-2, A7-2, A8/9-2 were used, respectively. Reactions were performed against total RNA with $(+)$ or without $(-)$ reverse transcription (RT).

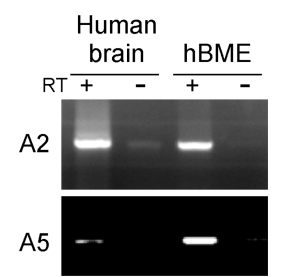

Fig. 2. mRNA Expression of ABCA2 and 5 in Human Brain and hBME Cells

RT-PCR analysis was performed with the specific primer sets shown in Table 1. Reactions were performed against total RNA with $(+)$ or without $(-)$ reverse transcription (RT).

trophoresis on agarose gel. All PCR products were subcloned and sequenced using a DNA sequencer (CEQ2000XL; Beckman Coulter, Fullerton, CA, U.S.A.).

\section{RESULTS}

mRNA expression was analyzed using 2 lines of TR-BBB cells, TR-BBB11 cells and TR-BBB13 cells (Fig. 1A). ABCA1, 2, 3, 4, 6, 7 and 8/9 were detected in both TRBBB11 and TR-BBB13 cells. ABCA5 was detected in TRBBB11 cells, but not in TR-BBB13 cells. The nucleotide sequences of the amplified products of ABCA1, 2 and 5 were identical to those of the corresponding rat genes. The sequences of the product of other subtypes had the highest homology with the corresponding mouse genes (ABCA3, 86\%; ABCA 4, 93\%; ABCA6, 89\%; ABCA7, 93\%; ABCA 8, 86\%; ABCA9, 92\%). This result indicates that the ABCA subtypes are expressed in TR-BBB cells.

The expression of $\mathrm{ABCA}$ subtypes at the $\mathrm{BBB}$ in vivo was examined in the rat brain capillary-rich fraction. mRNA expression of ABCA1, 2, 3, 4, 7 and 8/9 was detected (Fig. 1B). This suggests that these ABCA subtypes are expressed in rat BCECs. By using primer sets for ABCA6, multiple bands were detected at around the expected size (data not shown).

Expression in human BCECs was examined using hBME cells. Due to the limitation of the cDNA, RT-PCT was performed for one subtype in each ABCA1- and ABCA5-like 
subgroups, namely ABCA2 and 5, respectively. The amplified products of ABCA2 and 5 in hBME cells were detected at the same size as in human brain (Fig. 2). The nucleotide sequence of each product was identical to that of the corresponding human subtype. This result suggests that $\mathrm{ABCA} 2$ and 5 are expressed in human BCECs.

\section{DISCUSSION}

The present study examined the mRNA expression of ABCA subtypes in cultured rat and human BCECs (TR-BBB cells and hBME cells, respectively) and the rat brain capillary-rich fraction. The brain capillary-rich fraction is useful for detecting expression in the $\mathrm{BBB}$ in vivo, however, contamination by neural cells could not be ruled out. Indeed, ABCA1 was detected in cultured glial cells and neurons, ${ }^{16)}$ and $\mathrm{ABCA} 2$ is expressed in oligodendrocytes. ${ }^{17)}$ Cultured BCECs are free of any contamination, whereas immortalization affects gene expression. To minimize the difference in the gene expression between the in vivo $\mathrm{BBB}$ and cultured BCECs, we conducted PCR analysis using cultured rat and human BCECs and rat brain capillary-rich fraction. Furthermore, two different lines of TR-BBB cells were used to examine the line effect of immortalization on transporter expression. Among the ABCA subfamily, ABCA1 has been reported to be expressed in cultured porcine BCECs. ${ }^{9)}$ This study suggests that not only ABCA1 but also other ABCA subtypes are expressed at the $\mathrm{BBB}$.

ABCA4 has been identified as a gene, the mutation of which is linked to eye conditions, such as Startgardt's disease, ${ }^{18)}$ and it has been reported to be selectively expressed in the retina by Western blot analysis. ${ }^{19)}$ This study shows that ABCA4 is expressed in TR-BBB cells and the brain capillary-rich fraction (Fig. 1), suggesting that $\mathrm{ABCA} 4$ is expressed at the BBB. This is the first evidence to suggest that ABCA4 is expressed in tissues other than the retina. Since the volume of BCECs is only $0.1 \%$ of the total brain, the expression of ABCA4 could not be detected in the brain by Western blot analysis. There is a clinical report showing that neurological conditions, such as weakness of both arms and legs, and signs of demyelination at the cerebellum are found in a patients with Startgardt's disease. ${ }^{20)}$ Furthermore, ABCA4 has been suggested to mediate retinal transport, ${ }^{21)}$ and retinoids play important roles in CNS function and development. ${ }^{22)}$ Therefore, expression of ABCA4 in BCECs would explain the neurological symptoms in Startgardt's disease.

Expression of ABCA2, 3 and 7 has been reported to be induced by cholesterol. ${ }^{4-6)}$ The present study suggests that these subtypes are expressed at the BBB. Therefore, it is conceivable that the plasma and brain levels of cholesterol affect the expression of $\mathrm{ABCA} 2,3$ and 7 at the BBB. Interestingly, $\mathrm{ABCA} 2$ has also been suggested to act as a drug resistance gene, since $\mathrm{ABCA} 2$ protein is highly expressed in human ovarian cancer cells resistant to estramustine. ${ }^{23)} \mathrm{ABCA} 2$ is also expressed in hBME cells (Fig. 2). Therefore, it is possible that the cholesterol level affects the drug efflux process at the BBB.

The ABCA subfamily consists of two subgroups: one is the ABCA1-like subgroup formed with ABCA1, 2, 3, 4 and 7 , and the other is the ABCA5-like subgroup formed with
ABCA5, 6, 8 and 9. ${ }^{24)}$ Genes of the ABCA5-like subgroup cluster on human chromosome $17 .^{24)}$ Compared with the ABCA1-like subgroup, information about the ABCA5-like group is limited. ABCA5 mRNA was detected in TR-BBB cells, rat brain capillary-rich fraction and hBME cells (Figs. $1,2)$. mRNA expression of other transporters in the ABCA5like subgroup was also detected in TR-BBB cells (Fig. 1A). These results suggest that transporters in the ABCA5-like subgroup play roles in the rat and/or human BBB. ABCA5 mRNA was not detected in TR-BBB13 cells, while it was detected in TR-BBB11 cells, rat brain capillary-rich fraction and hBME cells (Figs. 1, 2). One possible explanation is down-regulation during cell culture. It is also conceivable that $\mathrm{ABCA} 5$ expression in the $\mathrm{BCECs}$ is heterogeneous in the brain, and TR-BBB11 and 13 cells were derived from different brain regions.

Among the ABCA5-like subgroup, $\mathrm{ABCA} 8$ has been reported to play a role in transport. ${ }^{25)}$ Unlike other $\mathrm{ABC}$ transporters, ABCA8 exhibited ATP-dependent uptake of organic anions, such as estrone sulfate, para-aminohippuric acid and estradiol- $\beta$-glucronide, in a Xenopus oocyte expression system. This indicates the possibility that ABCA8 functions as a new anion transport system at the BBB. ABCA8 and 9 have a high degree of homology, and the present PCR study could not distinguish these transporters by the sequence of the PCR product, since rat subtypes have not been reported, and ABCA9 was reported ${ }^{26)}$ after this PCR analysis was performed. Therefore, further PCR analysis is necessary using a primer set in the non-conserved region, e.g. the un-translated region, to distinguish between $\mathrm{ABCA} 8$ and 9.

In conclusion, the present study shows that various $\mathrm{ABCA}$ subtypes are expressed in cultured rat and human BCECs, suggesting the expression of $\mathrm{ABCA}$ subtypes at the BBB. This $\mathrm{BBB}$ expression of $\mathrm{ABCA}$ subtypes throws a new light on studies involving the $\mathrm{BBB}$. Therefore, the function and localization of ABCA subtypes at the BBB needs to be analyzed in further studies to gain a better understanding of BBB function.

Acknowledgements This study was supported, in part, by a Grant-in-Aid for Scientific Research from the Japan Society for the Promotion of Science, and a grant for the 21st Century Center of Excellence (COE) Program Special Research Grant from the Ministry of Education Science, Sports and Culture. It was also supported in part by the Industrial Technology Research Grant Program from New Energy and the Industrial Technology Development Organization (NEDO) of Japan.

\section{REFERENCES}

1) Ikeda Y., Abe-Dohmae S., Munehira Y., Aoki R., Kawamoto S., Furuya A., Shitara K., Amachi T., Kioka N., Matsuo M., Yokoyama S., Ueda K., Biochem. Biophys. Res. Commun., 311, 313-318 (2003).

2) Tanaka A. R., Ikeda Y., Abe-Dohmae S., Arakawa R., Sadanami K., Kidera A., Nakagawa S., Nagase T., Aoki R., Kioka N., Amachi T., Yokoyama S., Ueda K., Biochem. Biophys. Res. Commun., 283, 1019-1025 (2001).

3) Rust S., Rosier M., Funke H., Real J., Amoura Z., Piette J. C., Deleuze J. F., Brewer H. B., Duverger N., Denefle P., Assmann G., Nat. Genet., 22, 352-355 (1999).

4) Kaminski W. E., Piehler A., Pullmann K., Porsch-Ozcurumez M., Duong C., Bared G. M., Buchler C., Schmitz G., Biochem. Biophys. 
Res. Commun., 281, 249-258 (2001).

5) Kaminski W. E., Orso E., Diederich W., Klucken J., Drobnik W., Schmitz G., Biochem. Biophys. Res. Commun., 273, 532-538 (2000).

6) Klucken J., Buchler C., Orso E., Kaminski W. E., Porsch-Ozcurumez M., Liebisch G., Kapinsky M., Diederich W., Drobnik W., Dean M., Allikmets R., Schmitz G., Proc. Natl. Acad. Sci. U.S.A., 97, 817-822 (2000).

7) Hosoya K., Ohtsuki S., Terasaki T., Int. J. Pharm., 248, 15-29 (2002).

8) Bjorkhem I., Meaney S., Arterioscler. Thromb. Vasc. Biol., 24, 806815 (2004).

9) Panzenboeck U., Balazs Z., Sovic A., Hrzenjak A., Levak-Frank S., Wintersperger A., Malle E., Sattler W., J. Biol. Chem., 277, 4278142789 (2002).

10) Hosoya K. I., Takashima T., Tetsuka K., Nagura T., Ohtsuki S., Takanaga H., Ueda M., Yanai N., Obinata M., Terasaki T., J. Drug Target., 8, 357-370 (2000).

11) Terasaki T., Hosoya K., Biol. Pharm. Bull., 24, $111-118$ (2001).

12) Pardridge W. M., Drug Discov. Today, 9, 258 (2004).

13) Terasaki T., Ohtsuki S., Hori S., Takanaga H., Nakashima E., Hosoya K., Drug Discov. Today, 8, 944-954 (2003).

14) Umeki N., Fukusawa Y., Ohtsuki S., Hori S., Watanabe Y., Kohno Y., Terasaki T., Drug Metab. Pharmacokin., 17, 367-363 (2002).

15) Hori S., Ohtsuki S., Tachikawa M., Kimura N., Kondo T., Watanabe
M., Nakashima E., Terasaki T., J. Neurochem., 90, 526-536 (2004).

16) Fukumoto H., Deng A., Irizarry M. C., Fitzgerald M. L., Rebeck G. W., J. Biol. Chem., 277, 48508-48513 (2002).

17) Tanaka Y., Yamada K., Zhou C. J., Ban N., Shioda S., Inagaki N., J. Comp. Neurol., 455, 353-367 (2003).

18) Allikmets R., Shroyer N. F., Singh N., Seddon J. M., Lewis R. A., Bernstein P. S., Peiffer A., Zabriskie N. A., Li Y., Hutchinson A., Dean M., Lupski J. R., Leppert M., Science, 277, 1805-1807 (1997).

19) Azarian S. M., Travis G. H., FEBS Lett., 409, 247-252 (1997).

20) Kalfakis N., Grivas I., Panayiotidou E., Sfagos C., Papageorgiou C., Funct. Neurol., 9, 97-100 (1994).

21) Sun H., Nathans J., J. Biol. Chem., 276, 11766-11774 (2001).

22) Wolf G., Nutr. Rev., 56, 354-355 (1998).

23) Laing N. M., Belinsky M. G., Kruh G. D., Bell D. W., Boyd J. T., Barone L., Testa J. R., Tew K. D., Cancer Res., 58, 1332-1337 (1998).

24) Dean M., Hamon Y., Chimini G., J. Lipid Res., 42, 1007-1017 (2001).

25) Tsuruoka S., Ishibashi K., Yamamoto H., Wakaumi M., Suzuki M., Schwartz G. J., Imai M., Fujimura A., Biochem. Biophys. Res. Commun., 298, 41-45 (2002).

26) Piehler A., Kaminski W. E., Wenzel J. J., Langmann T., Schmitz G., Biochem. Biophys. Res. Commun., 295, 408-416 (2002). 